Original Article

\title{
Association between interstitial cells of Cajal and anti-vinculin antibody in human stomach
}

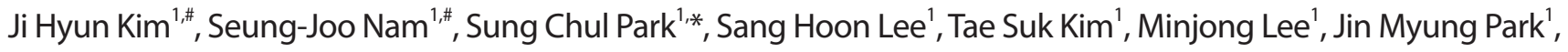 \\ Dae Hee Choi ', Chang Don Kang', Sung Joon Lee', Young Joon Ryu' ${ }^{2}$, Kyungyul Lee', and So Young Park ${ }^{3}$
}

Departments of ${ }^{1}$ Internal Medicine and ${ }^{2}$ Pathology, Kangwon National University School of Medicine, ${ }^{3}$ Kangwon National University Institute of Medical Science, Chuncheon 24289, Korea

\section{ARTICLE INFO}

Received November 18, 2019

Revised February 1, 2020

Accepted February 4, 2020

*Correspondence

Sung Chul Park

E-mail: schlp@hanmail.net

\section{Key Words}

Gastrointestinal motility

Interstitial cells of Cajal

Stomach

Vinculin

\#These authors contributed equally to this work.
ABSTRACT Interstitial cells of Cajal (ICC) are known as the pacemaker cells of gastrointestinal tract, and it has been reported that acute gastroenteritis induces intestinal dysmotility through antibody to vinculin, a cytoskeletal protein in gut, resulting in small intestinal bacterial overgrowth, so that anti-vinculin antibody can be used as a biomarker for irritable bowel syndrome. This study aimed to determine correlation between serum anti-vinculin antibody and ICC density in human stomach. Gastric specimens from 45 patients with gastric cancer who received gastric surgery at Kangwon National University Hospital from 2013 to 2017 were used. ICC in inner circular muscle, and myenteric plexus were counted. Corresponding patient's blood samples were used to determine the amount of anti-vinculin antibody by enzyme-linked immunosorbent assay. Analysis was done to determine correlation between anti-vinculin antibody and ICC numbers. Patients with elevated anti-vinculin antibody titer (above median value) had significantly lower number of ICC in inner circular muscle (71.0 vs. 240.5, $p=0.047$ ), and myenteric plexus (12.0 vs. $68.5, p<0.01$ ) compared to patients with lower anti-vinculin antibody titer. Level of serum anti-vinculin antibody correlated significantly with density of ICC in myenteric plexus ( $r=-0.379$, $p=0.01$; Spearman correlation). Increased level of circulating anti-vinculin antibody was significantly correlated with decreased density of ICC in myenteric plexus of human stomach.

\section{INTRODUCTION}

Functional gastrointestinal disorders (FGID) are the most common disease in gastroenterology. Although exact etiology and pathophysiology of FGID have not been identified yet, many risk factors are known to contribute to the development of FGID, including diet, genetic factors, infection, immune activation, and stress [1]. Infection has been considered an important factor for development of FGID [2-5]. A study on children with positive bacterial stool culture reported that $87 \%$ of infected children developed irritable bowel syndrome (IBS) and $24 \%$ had dyspepsia [6], an observational study on subjects exposed to outbreak of bacterial dysentery in Canada reported that up to $42.6 \%$ developed dyspepsia in 8 year follow up time [2], while a study on pathogen specific cases such as Campylobacter, Salmonella, Shigella, Yersinia, showed patients with specific infectious pathogen had increased risk of developing IBS, dyspepsia, constipation, and gastroesophageal reflux disease [7].

In recent studies, rats gavaged with Campylobacter jejuni showed small intestinal bacterial overgrowth (SIBO), elevated cytolethal distending toxin B (CdtB), and decreased number of interstitial cells of Cajal (ICC) in the deep muscular plexus [8-12]. (i) (8) This is an Open Access article distributed under the terms of the Creative Commons Attribution Non-Commercial License, which permits unrestricted non-commercial use, distribution, and reproduction in any medium, provided the original work is properly cited. Copyright $\odot$ Korean J Physiol Pharmacol, pISSN 1226-4512, elSSN 2093-3827
Author contributions: J.H.K. and S.J.N. equally contributed to this work; J.H.K. and S.C.P. designed the study; S.J.N., S.H.L., T.S.K., M.L., J.M.P., D.H.C., C.D.K., S.J.L. contributed to the conception of the study; J.H.K., Y.J.R., and S.Y.P. performed the experiments; J.H.K., S.J.N., and S.C.P. analyzed the data and wrote the paper. 
Reduction in ICC in myenteric plexus was also reported in human IBS subjects with presence of SIBO [12]. Study by Pimentel et al. [13] reported that when ileal tissues of human, $C$. jejuniinfected and naïve rats were analyzed using antibodies to $\mathrm{CdtB}$ which is common to all pathogens causing acute gastroenteritis, antibodies to $\mathrm{CdtB}$ were found bound to protein in ICC, which was later identified as vinculin. When compared to infection naive rats, amount of $\mathrm{CdtB}$ antibodies were higher in rats infected with $C$. jejuni while cytosolic protein vinculin was lower, and suggested cross-reaction of $\mathrm{CdtB}$ antibodies with vinculin in ICC, resulting in formation of autoimmunity against vinculin. Vinculin is a cytoplasmic protein that localizes at cell-matrix adhesions and cell-cell junctions required for normal gut motility [14], and ICC have been identified as pacemaker cells of the GI tract that mediate neurotransmission and motility by generating slow waves [15]. Study on human stomach and colon obtained from bariatric and colon cancer patients showed that ICC decreased with increasing age [16], while alterations in density of ICC have been known to be involved in many GI disorders such as ulcerative colitis, Crohn's disease, slow-transit constipation and pseudo-obstruction [17,18]. Also, study on patients with diabetes mellitus (DM) showed that lower gastric ICC may be associated with pathogenesis of gastroparesis $[19,20]$.

As it was observed from previous study that antibodies to $\mathrm{CdtB}$ were bound to ICC in ileum tissue of humans without history of IBS or inflammatory bowel disease, and suggested that crossreactivity produces anti-vinculin antibody that binds to vinculin of ICC with reduction of ICC observed, our study aimed to investigate if circulating levels of anti-vinculin antibody correlates with number of ICC in human stomach, as ICC are known to be found throughout the GI tract.

\section{METHODS}

\section{Patient tissue and serum samples}

Gastric specimens fixed in 10\% formalin were collected from 45 patients who received gastrectomy at Kangwon National University Hospital due to gastric cancer between 2013 and 2017. All patients did not receive radiotherapy prior to surgery, and they were not diagnosed with GI disorders other than gastric cancer. Nine patients were diagnosed with DM prior to surgery. All specimens were obtained from the antrum of each resected stomach, and cancerous lesions were not included. The biospecimens for this study were provided by the Kangwon National University Hospital Biobank, a member of the National Biobank of Korea, which is supported by the Ministry of Health, Welfare and Family Affairs. All samples derived from the National Biobank of Korea were obtained with informed consent under institutional review board-approved protocols.

Written informed consent was obtained from each patient prior to the study, and the Institutional Review Board of Kangwon National University Hospital approved research protocol in advance (IRB No. KWNUH 2017-06-001). This study was conducted in accordance with provisions of the Declaration of Helsinki.

\section{Immunohistochemistry}

Paraffin-embedded specimens were sectioned ( $4 \mu \mathrm{m}$ thick) and mounted on glass slides. To examine the distribution of ICC, serial sections were stained for DOG-1 (discovered on gastrointestinal stromal tumor 1 [GIST-1]). Briefly, after deparaffinizing in xylene and rehydrating in ethanol, the sections were heated in citrate buffer $(0.01 \mathrm{M}, \mathrm{pH} 6.0)$ in a microwave $(600 \mathrm{~W})$ for $10 \mathrm{~min}$ to retrieve antigens. Next, the sections were incubated with $3 \%$ hydrogen peroxide for $10 \mathrm{~min}$ to block endogenous peroxidase, before incubating with the primary mouse monoclonal antiDOG-1 antibody (1:100; Roche, Basel, Schweiz) overnight at $4^{\circ} \mathrm{C}$. The sections were processed using an autostainer (XT System Benchmark; Ventana Medical System, Tucson, AZ, USA) according to the manufacturer's instruction.

\section{Cell count}

Two independent investigators who were blinded to the clinical information counted the number of DOG-1 positive cells in each slide. The number of DOG-1 positive cells in the inner circular muscle and myenteric plexus in the antrum were counted in ten randomly selected $0.25 \mathrm{~mm}^{2}$ field from each specimen under a microscope at a magnification of $200 \times$ (Fig. 1).

\section{Enzyme-linked immunosorbent assay (ELISA) of sera}

Plasma samples were collected by venipuncture into a lavendertop tube, then centrifuged at 3,500 rpm for $15 \mathrm{~min}$, and stored at $-80^{\circ} \mathrm{C}$ until analysis. ELISA was conducted using a recombinant vinculin (Novoprotein, Short Hills, NJ, USA) as antigen. Antigen $(1.2 \mu \mathrm{g} / \mathrm{ml})$ was immobilized overnight at $4^{\circ} \mathrm{C}$ onto highbinding 96-well plates (Grenier Bio-One, Monroe, NC, USA) in Borate Buffered Saline (Medicago, Uppsala, Sweden) at a $\mathrm{pH}$ of 8.2. Individual plates were coated with vinculin, and half of each plate contained uncoated wells to determine and control for non-specific binding of sera. Wells were blocked with $3 \%$ bovine serum albumin in phosphate buffered saline (PBS) for $1 \mathrm{~h}$ at room temperature. Human sera were diluted at 1:32 dilution and added in triplicate to both coated and uncoated wells for $1 \mathrm{~h}$ at room temperature. Antibodies to vinculin were used as positive control. HRP-conjugated secondary antibodies (Jackson ImmunoResearch, West Grove, PA, USA) were then added to the wells and incubated for $1 \mathrm{~h}$. Each step was followed by a series of plate washes using $0.05 \%$ PBS-T. Finally, a TMB substrate solution (Pierce, Rockford, IL, USA) was used for visualization and immediately read on a BioTek Synergy HT plate reader. 
A

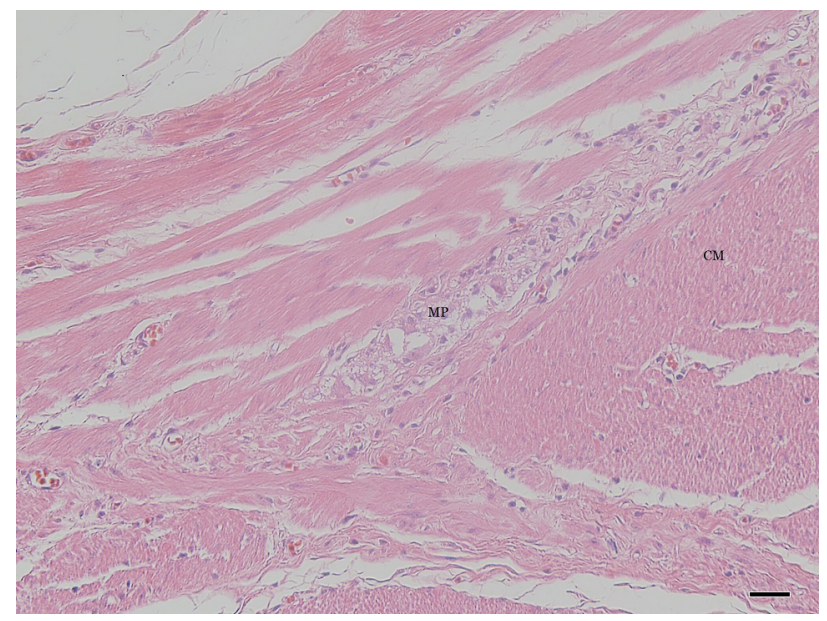

B

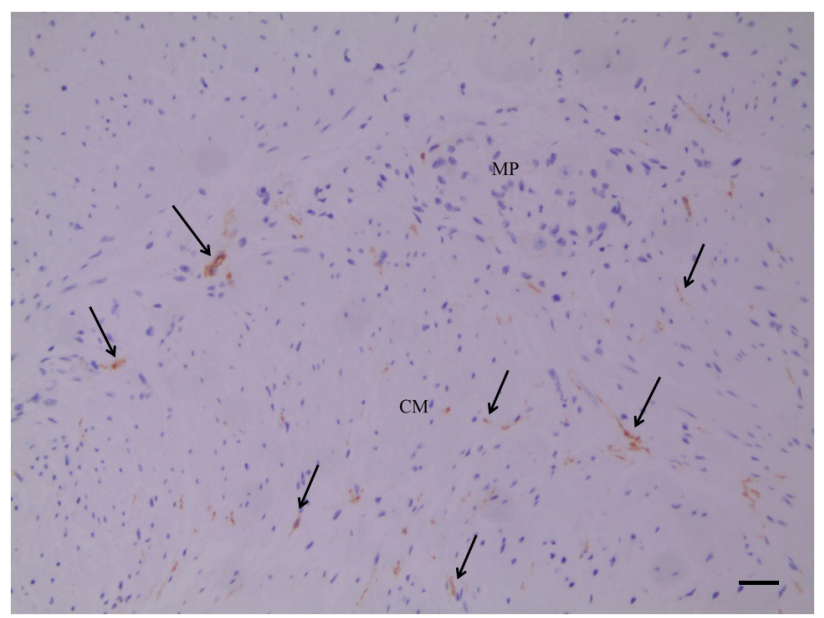

Fig. 1. ICC in the antrum of human stomach. Sections from paraffin-enbedded control samples stained with H\&E (A) and DOG-1 antibody (B). Original magnification, 200x. Bar, $20 \mu \mathrm{m}$. Arrows: positively stained ICC. ICC, interstitial cells of Cajal; CM, circular muscle; MP, myenteric plexus.

Table 1. Baseline characteristics

\begin{tabular}{lc}
\hline \multicolumn{1}{c}{ Variable } & Total $(\mathrm{n}=45)$ \\
\hline Sex & \\
Male & $36(80.0)$ \\
Female & $9(20.0)$ \\
Age & $66(57.5-73.0)$ \\
Diabetes mellitus & $9(20.0)$ \\
\hline
\end{tabular}

Values are presented as number (\%) or median (interquartile range).

\section{Statistical analysis}

Comparisons of anti-vinculin antibody levels and ICC counts in inner circular muscle and myenteric plexus were done by the non-parametric Mann-Whitney U-test. Correlation curves between anti-vinculin antibody and ICC counts were compared by Spearman correlation. Significance was defined as $p<0.05$, and data are expressed in median and interquartile range (IQR). Data were analyzed with SPSS version 23.0 (IBM Co., Armonk, NY, USA).

\section{RESULTS}

\section{Baseline characteristics}

The median age of patients was 66 years (IQR 57.5-73.0). 36 patients (80.0\%) were male, and 9 patients (20.0\%) were female. Nine patients (20.0\%) were diagnosed with DM before gastrectomy (Table 1).
Table 2. Anti-vinculin antibody titer according to clinical characteristics

\begin{tabular}{lcc}
\hline Variable & Anti-vinculin antibody $(\mathrm{ng} / \mathrm{ml})$ & p-value \\
\hline Total & $121.7(44.6-450.6)$ & \\
Sex & & $0.02^{*}$ \\
Male & $105.7(42.1-296.0)$ & \\
Female & $662.6(70.5-1,061.2)$ & \\
Age $(\mathrm{yr})$ & & $0.07^{*}$ \\
$<65$ & $74.2(0.0-413.9)$ & \\
$\geq 65$ & $173.1(77.5-526.3)$ & \\
\hline
\end{tabular}

Values are presented as median (interquartile range). ${ }^{*}$ p-value estimated by Mann-Whitney U-test for continuous variables.

\section{Anti-vinculin antibody titer}

The median titer of serum anti-vinculin antibody was 121.7 $\mathrm{ng} / \mathrm{ml}$ (IQR $44.6-450.6 \mathrm{ng} / \mathrm{ml}$ ). When compared by sex, anti-vinculin antibody was significantly lower in male $(105.7 \mathrm{ng} / \mathrm{ml}, \mathrm{IQR}$ $42.1-296.0 \mathrm{ng} / \mathrm{ml})$ than female $(662.6 \mathrm{ng} / \mathrm{ml}$, IQR $70.5-1,061.2 \mathrm{ng} /$ $\mathrm{ml})(\mathrm{p}=0.02)$ (Table 2). When patients were divided into group with ages under 65 years and group with ages over 65 , patients with ages under 65 had relatively lower anti-vinculin antibody $(74.2 \mathrm{ng} / \mathrm{ml}$, IQR $0.0-413.9 \mathrm{ng} / \mathrm{ml})$ than patients above 65 (173.1 $\mathrm{ng} / \mathrm{ml}$, IQR 77.5-526.3 ng/ml) ( $\mathrm{p}=0.07)$.

\section{Antral ICC number}

Median number of ICC in the inner circular muscle was 151.0 per $2.5 \mathrm{~mm}^{2}$ (IQR $24.5-319.0$ per $2.5 \mathrm{~mm}^{2}$ ), while median number of ICC in the myenteric plexus was 28.0 per $2.5 \mathrm{~mm}^{2}$ (IQR $5.5-83.0$ per $2.5 \mathrm{~mm}^{2}$ ) (Table 3).

When compared by sex, median number of ICC in the inner circular muscle of male was 151.5 per $2.5 \mathrm{~mm}^{2}$ (IQR 24.3-369.8 
Table 3. ICC number according to clinical characteristics

\begin{tabular}{|c|c|c|c|c|}
\hline Variable & ICC-IM (ICC number) & p-value* & ICC-MP (ICC number) & p-value* \\
\hline Total & $151.0(24.5-319.0)$ & & $28.0(5.5-83.0)$ & \\
\hline Sex & & 0.73 & & 0.88 \\
\hline Male & $151.5(24.3-369.8)$ & & $30.5(4.3-89.5)$ & \\
\hline Female & $151.0(23.5-300)$ & & $25.0(7.0-66.5)$ & \\
\hline Age $(y r)$ & & 0.25 & & 0.57 \\
\hline$<65$ & $43.5(1.5-452.0)$ & & $35.0(2.3-85.5)$ & \\
\hline$\geq 65$ & $177.0(66.5-317)$ & & $28.0(10.0-80.5)$ & \\
\hline Vinculin (ng/ml) & & 0.047 & & 0.005 \\
\hline$<121.7$ & $240.5(52.8-360.0)$ & & $68.5(21.0-109.3)$ & \\
\hline$\geq 121.7$ & $71.0(4.0-190.0)$ & & $12.0(2.0-52.0)$ & \\
\hline
\end{tabular}

Values are presented as median (interquartile range). ICC, interstitial cells of Cajal; ICC-IM, ICC in circular muscle; ICC-MP, ICC in myenteric plexus. *p-value estimated by Mann-Whitney U-test for continuous variables.
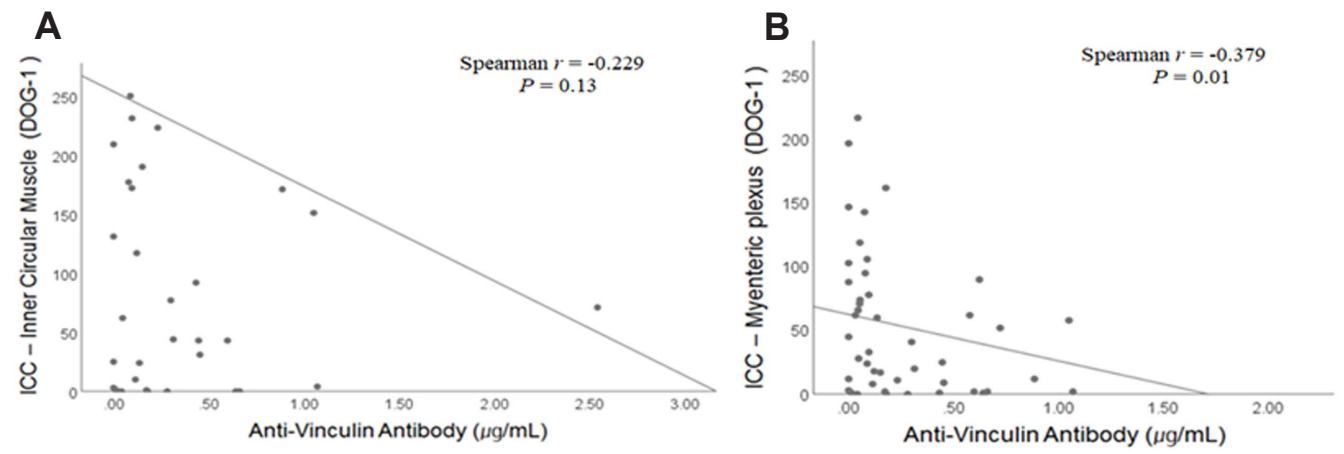

Fig. 2. Correlation between anti-vinculin antibody and ICC. Spearman correlation graph between anti-vinculin antibody and ICC number in circular muscle (A) and myenteric plexus (B). ICC, interstitial cells of Cajal; DOG-1, discovered on GIST-1; GIST-1, gastrointestinal stromal tumor 1.

per $2.5 \mathrm{~mm}^{2}$ ), while in female the median number of ICC in inner circular muscle was 151.0 per $2.5 \mathrm{~mm}^{2}$ (IQR 23.5-300.0 per $\left.2.5 \mathrm{~mm}^{2}\right)(\mathrm{p}=0.73)$. The median number of ICC in the myenteric plexus observed in male was 30.5 per $2.5 \mathrm{~mm}^{2}$ (IQR $4.3-89.5$ per $2.5 \mathrm{~mm}^{2}$ ), while in female the median number of ICC in myenteric plexus was 25.0 per $2.5 \mathrm{~mm}^{2}$ (IQR 7.0-66.5 per $\left.2.5 \mathrm{~mm}^{2}\right)(\mathrm{p}=$ 0.88) (Table 3).

When compared by age, median number of ICC in inner circular muscle of patients under 65 years was 43.5 per $2.5 \mathrm{~mm}^{2}$ (IQR $1.5-452.0$ per $2.5 \mathrm{~mm}^{2}$ ), while in patients above 65 the median number of ICC in inner circular muscle was 177.0 per $2.5 \mathrm{~mm}^{2}$ (IQR 66.5-317.0 per $\left.2.5 \mathrm{~mm}^{2}\right)(\mathrm{p}=0.25)$. The median number of ICC in the myenteric plexus observed in patients under 65 was 35.0 per $2.5 \mathrm{~mm}^{2}$ (IQR $2.3-85.5$ per $2.5 \mathrm{~mm}^{2}$ ), while in patients over 65 the median number of ICC in myenteric plexus was 28.0 per $2.5 \mathrm{~mm}^{2}$ (IQR $10.0-80.5$ per $\left.2.5 \mathrm{~mm}^{2}\right)(\mathrm{p}=0.57)$ (Table 3).

Twenty-two patients with elevated anti-vinculin antibody titer (above median value of $121.7 \mathrm{ng} / \mathrm{ml}$ ) had significantly lower number of ICC in inner circular muscle (71.0, $\mathrm{p}=0.047$ ), and myenteric plexus $(12.0, \mathrm{p}<0.01)$ compared to 23 patients with lower anti-vinculin antibody titer (below median value) which were 240.5 in inner circular muscle and 68.5 in myenteric plexus (Table 3).

\section{Correlation between anti-vinculin antibody and antral ICC}

In general, anti-vinculin antibody was negatively correlated with ICC density (Fig. 2). Significant correlation was found between anti-vinculin antibody and ICC in myenteric plexus ( $\mathrm{r}=$ $-0.379, \mathrm{p}=0.01)$. Spearman correlation between anti-vinculin antibody and ICC in inner circular muscle was $r=-0.229(\mathrm{p}=$ 0.13) (Fig. 2). In male patients, correlation between anti-vinculin antibody and ICC in inner circular muscle was $\mathrm{r}=-0.112(\mathrm{p}=$ $0.52)$, while myenteric plexus was $r=-0.326(p=0.05)$. In female patients, correlation between anti-vinculin antibody and ICC in inner circular muscle was $r=-0.583(p=0.10)$, while myenteric plexus was $r=-0.689(p=0.04)$.

In patients under 65 , correlation between anti-vinculin antibody and ICC in inner circular muscle was $r=-0.232(p=0.33)$, while myenteric plexus was $r=-0.246(p=0.30)$. In patients above 65 , correlation between anti-vinculin antibody and ICC in inner circular muscle was $\mathrm{r}=-0.489(\mathrm{p}=0.01)$, while myenteric plexus was $r=-0.589(\mathrm{p}<0.01)$. 


\section{DISCUSSION}

To explore the association between serum anti-vinculin antibody and ICC number in human stomach, we compared serum anti-vinculin antibody titer with ICC number in inner circular muscle, and myenteric plexus. The results have shown that patients with elevated anti-vinculin antibody had significantly reduced number of ICC in both inner circular muscle and myenteric plexus. Also increased level of circulating anti-vinculin antibody was significantly correlated with decreased number of ICC in myenteric plexus of human stomach $(\mathrm{p}=0.01)$. Similar trends were also observed between anti-vinculin antibody titer and ICC in inner circular muscle, but without statistical significance. To our knowledge, this is the first attempt to investigate the correlation between anti-vinculin antibody and ICC density in human stomach.

ICC is type of interstitial cells of GI tract, known as the pacemaker cells that generate spontaneous slow waves in GI tract and also as stretch receptor to regulate motility [21]. Disruption or lack of ICC has been known to result in GI motility diseases such as idiopathic gastroparesis and functional dyspepsia, and previous studies have shown that ICC of GI tract are also decreased in patients with DM, elderly, and also in animal models with SIBO suggesting that reduction in ICC may be contributing factor in abnormal GI motility $[8,13,16,20]$. Among different subtypes of ICC, myenteric plexus ICC (ICC-MP) located in the space between circular and longitudinal muscle layer, are known to function as pacemaker cells that generate slow wave potential, while intramuscular ICC (ICC-IM) stimulate smooth muscle cells. Studies on distribution of ICC in GI tract showed uneven distribution throughout the GI tract, and human specimens have shown that ICC-IM was much higher at circular muscle layer than at longitudinal muscle layer [21].

ICC is commonly stained with c-Kit as it is a proto-oncogene expressed by ICC, our study used DOG-1 stain for identification of ICC [21]. DOG-1 is a transmembrane protein with calciumactivated chloride channel (anoctamin 1) that was first discovered with high positivity for gastrointestinal stromal tumor [22]. Studies have suggested that DOG-1 is a more specific marker for identification of ICC than c-Kit, and anoctamin 1 may be involved in generation of slow waves in ICC of GI tract [23-25].

Vinculin is an actin-binding membrane-cytoskeletal protein associated with cell-cell and cell-matrix junctions, neuronal cell motility, contractility, and epithelial barrier formation $[14,26]$. Study on rats infected with $C$. jejuni reported that when ileal tissues obtained from rats gavaged with $C$. jejuni were stained with antibodies to $\mathrm{CdtB}$, antibodies had bound to protein in ICC and neurons, which was analyzed to be protein vinculin. Similar findings, although to a lesser degree, were observed on rats that were not gavaged with $C$. jejuni and even in human ileal tissues obtained from patients who underwent hemicolectomy for colon cancer. Such findings were explained by molecular mimicry between CdtB and vinculin, and suggested that autoimmunity may play an important role [13]. Vinculin expression was found to be decreased in rat model following $C$. jejuni infection, while anti-vinculin antibody was elevated. Study by Rezaie et al. [27] reported that human subjects with IBS with diarrhea (IBS-D) had highest levels of anti-CdtB and anti-vinculin antibodies while IBS with constipation (IBS-C) and health controls had lowest, and suggested possible use of vinculin as a biomarker for IBSD. These data suggest that as antibody to vinculin increases in serum, expression of vinculin in ICC decreases. As cytoskeletal protein, vinculin is an important component to structural integrity, and it is plausible that formation of antibody to vinculin may cause unstable cellular integrity that result in reduction of ICC.

Consistent with this hypothesis, our results showed that the patients with elevated levels of serum anti-vinculin antibody had significantly reduced number of ICC in the stomach specimens compared to the patients with lower levels of anti-vinculin antibody. As anti-vinculin antibody has been shown to bind to vinculin protein in ICC in the previous study, the results from this study may suggest possible role of vinculin in expression of gastric ICC [13]. It has been reported that rats gavaged with Campylobacter jejuni had SIBO, and lower number of small bowel ICC in deep muscular plexus [8]. SIBO was also associated with increased $\mathrm{CdtB}$ antibody and vinculin antibody in similar animal model. In our study, increased level of vinculin antibody was significantly correlated with decreased number of ICC-MP ( $\mathrm{p}=$ 0.01 ), while it also correlated with decreased number of ICC-IM without statistical significance $(\mathrm{p}=0.13)$. Such findings may suggest that ICC-MP should play more important role in signaling pathway of vinculin antibody than ICC-IM. It has potential implications for understanding the role of anti-vinculin antibody in upper GI motility disorders such as functional dyspepsia as well as lower GI motility disorders such as IBS with reported evidence of immunologic pathogenesis. However, this is just a correlation study and further research is needed.

There are many limitations in this study. Although this study aimed to determine correlation between ICC and anti-vinculin antibody, its significance in specific GI symptoms could not be analyzed as this was a retrospective study based on chart review. ICC has been known to decrease with some motility disorders, but we could not include functional studies such as gastric emptying scan of each patients as it is not included in routine evaluation before gastric cancer surgery. Another limitation is that all patients in this study had been diagnosed with gastric cancer. Although there have been no reports on correlation between ICC, vinculin, and gastric cancer, it could also be a factor that affects both anti-vinculin antibody and ICC. Also, small number of study population is another limitation, as this was a single center retrospective study using stomach specimens obtained from surgery.

In conclusion, our results have shown that patients with higher vinculin antibody had significantly decreased ICC in both cir- 
cular muscle and myenteric plexus of human stomach. Also, increased vinculin antibody was significantly correlated with decreased ICC in myenteric plexus of human stomach. Further studies are needed to determine if expression of gastric ICC may be regulated by anti-vinculin antibodies and its role in upper GI dysmotility disorders.

\section{ACKNOWLEDGEMENTS}

This study was supported by 2017 Kangwon National University Hospital Grant.

\section{CONFLICTS OF INTEREST}

The authors declare no conflicts of interest.

\section{REFERENCES}

1. David LA, Maurice CF, Carmody RN, Gootenberg DB, Button JE, Wolfe BE, Ling AV, Devlin AS, Varma Y, Fischbach MA, Biddinger SB, Dutton RJ, Turnbaugh PJ. Diet rapidly and reproducibly alters the human gut microbiome. Nature. 2014;505:559-563.

2. Ford AC, Thabane M, Collins SM, Moayyedi P, Garg AX, Clark WF, Marshall JK. Prevalence of uninvestigated dyspepsia 8 years after a large waterborne outbreak of bacterial dysentery: a cohort study. Gastroenterology. 2010;138:1727-1736; quiz el2.

3. Halvorson HA, Schlett CD, Riddle MS. Postinfectious irritable bowel syndrome--a meta-analysis. Am J Gastroenterol. 2006;101:18941899; quiz 1942.

4. Lovell RM, Ford AC. Global prevalence of and risk factors for irritable bowel syndrome: a meta-analysis. Clin Gastroenterol Hepatol. 2012;10:712-721.e4.

5. Mearin F, Pérez-Oliveras M, Perelló A, Vinyet J, Ibañez A, Coderch J, Perona M. Dyspepsia and irritable bowel syndrome after a Salmonella gastroenteritis outbreak: one-year follow-up cohort study. Gastroenterology. 2005;129:98-104.

6. Saps M, Pensabene L, Di Martino L, Staiano A, Wechsler J, Zheng X, Di Lorenzo C. Post-infectious functional gastrointestinal disorders in children. J Pediatr. 2008;152:812-816, 816.el.

7. Porter CK, Choi D, Cash B, Pimentel M, Murray J, May L, Riddle MS. Pathogen-specific risk of chronic gastrointestinal disorders following bacterial causes of foodborne illness. BMC Gastroenterol. 2013;13:46.

8. Jee SR, Morales W, Low K, Chang C, Zhu A, Pokkunuri V, Chatterjee S, Soffer E, Conklin JL, Pimentel M. ICC density predicts bacterial overgrowth in a rat model of post-infectious IBS. World J Gastroenterol. 2010;16:3680-3686.

9. Nieuwenhuijs VB, Verheem A, van Duijvenbode-Beumer H, Visser MR, Verhoef J, Gooszen HG, Akkermans LM. The role of interdigestive small bowel motility in the regulation of gut microflora, bacterial overgrowth, and bacterial translocation in rats. Ann Surg. 1998;228:188-193.
10. Pimentel M, Chatterjee S, Chang C, Low K, Song Y, Liu C, Morales W, Ali L, Lezcano S, Conklin J, Finegold S. A new rat model links two contemporary theories in irritable bowel syndrome. Dig Dis Sci. 2008;53:982-989.

11. Pimentel M, Soffer EE, Chow EJ, Kong Y, Lin HC. Lower frequency of MMC is found in IBS subjects with abnormal lactulose breath test, suggesting bacterial overgrowth. Dig Dis Sci. 2002;47:26392643.

12. Vantrappen G, Janssens J, Hellemans J, Ghoos Y. The interdigestive motor complex of normal subjects and patients with bacterial overgrowth of the small intestine. JClin Invest. 1977;59:1158-1166.

13. Pimentel M, Morales W, Pokkunuri V, Brikos C, Kim SM, Kim SE, Triantafyllou K, Weitsman S, Marsh Z, Marsh E, Chua KS, Srinivasan S, Barlow GM, Chang C. Autoimmunity links vinculin to the pathophysiology of chronic functional bowel changes following campylobacter jejuni infection in a rat Model. Dig Dis Sci. 2015;60:1195-1205.

14. Bays JL, DeMali KA. Vinculin in cell-cell and cell-matrix adhesions. Cell Mol Life Sci. 2017;74:2999-3009.

15. Yin J, Chen JD. Roles of interstitial cells of Cajal in regulating gastrointestinal motility: in vitro versus in vivo studies. J Cell Mol Med. 2008;12:1118-1129.

16. Gomez-Pinilla PJ, Gibbons SJ, Sarr MG, Kendrick ML, Shen KR, Cima RR, Dozois EJ, Larson DW, Ordog T, Pozo MJ, Farrugia G. Changes in interstitial cells of cajal with age in the human stomach and colon. Neurogastroenterol Motil. 2011;23:36-44.

17. Jain D, Moussa K, Tandon M, Culpepper-Morgan J, Proctor DD. Role of interstitial cells of Cajal in motility disorders of the bowel. Am J Gastroenterol. 2003;98:618-624.

18. Porcher C, Baldo M, Henry M, Orsoni P, Julé Y, Ward SM. Deficiency of interstitial cells of Cajal in the small intestine of patients with Crohn's disease. Am J Gastroenterol. 2002;97:118-125.

19. Horváth VJ, Vittal H, Lörincz A, Chen H, Almeida-Porada G, Redelman D, Ordög T. Reduced stem cell factor links smooth myopathy and loss of interstitial cells of cajal in murine diabetic gastroparesis. Gastroenterology. 2006;130:759-770.

20. Iwasaki H, Kajimura M, Osawa S, Kanaoka S, Furuta T, Ikuma M, Hishida A. A deficiency of gastric interstitial cells of Cajal accompanied by decreased expression of neuronal nitric oxide synthase and substance $\mathrm{P}$ in patients with type 2 diabetes mellitus. J Gastroenterol. 2006;41:1076-1087.

21. Yun HY, Sung R, Kim YC, Choi W, Kim HS, Kim H, Lee GJ, You RY, Park SM, Yun SJ, Kim MJ, Kim WS, Song YJ, Xu WX, Lee SJ. Regional distribution of interstitial cells of Cajal (ICC) in human stomach. Korean J Physiol Pharmacol. 2010;14:317-324.

22. Lee $\mathrm{CH}$, Liang $\mathrm{CW}$, Espinosa I. The utility of discovered on gastrointestinal stromal tumor 1 (DOG1) antibody in surgical pathologythe GIST of it. Adv Anat Pathol. 2010;17:222-232.

23. Gomez-Pinilla PJ, Gibbons SJ, Bardsley MR, Lorincz A, Pozo MJ, Pasricha PJ, Van de Rijn M, West RB, Sarr MG, Kendrick ML, Cima RR, Dozois EJ, Larson DW, Ordog T, Farrugia G. Anol is a selective marker of interstitial cells of Cajal in the human and mouse gastrointestinal tract. Am J Physiol Gastrointest Liver Physiol. 2009; 296:G1370-G1381.

24. Hwang SJ, Blair PJ, Britton FC, O’Driscoll KE, Hennig G, Bayguinov YR, Rock JR, Harfe BD, Sanders KM, Ward SM. Expression of anoctamin 1/TMEM16A by interstitial cells of Cajal is fundamental 
for slow wave activity in gastrointestinal muscles. J Physiol. 2009; 587(Pt 20):4887-4904.

25. Zhu MH, Kim TW, Ro S, Yan W, Ward SM, Koh SD, Sanders KM. $\mathrm{A} \mathrm{Ca}^{2+}$-activated $\mathrm{Cl}^{-}$conductance in interstitial cells of Cajal linked to slow wave currents and pacemaker activity. J Physiol. 2009;587(Pt 20):4905-4918.
26. Critchley DR. Cytoskeletal proteins talin and vinculin in integrinmediated adhesion. Biochem Soc Trans. 2004;32(Pt 5):831-836.

27. Rezaie A, Park SC, Morales W, Marsh E, Lembo A, Kim JH, Weitsman S, Chua KS, Barlow GM, Pimentel M. Assessment of anti-vinculin and anti-cytolethal distending toxin B antibodies in subtypes of irritable bowel syndrome. Dig Dis Sci. 2017;62:1480-1485. 